\title{
JUURNAL.RU
}

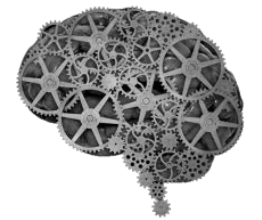

COMPANY GROUP "INTELLEKT"

Макаревич В.Г., Костеша Н.Я. ФГБОУ ВО Новосибирский государственный аграрный университет

Новосибирск, Россия

doi: 10.18411/lj2016-5-1-11

\section{Изменение морфологического состава крови у телят при использовании биовестина}

\begin{abstract}
Аннотация:
В эксперимент были взяты 2 группы телят. Опытной группе с рождения до 21 -го дня жизни дополнительно выпаивался «Биовестин». Контрольная группа находилась в аналогичных условиях кормления и содержания, однако биовестин не получала. Исследование периферической крови показало, что в опытной группе телят содержание эритроцитов достоверно увеличивалось относительно контрольной группы. Со стороны лейкограммы наблюдалась картина, характеризующая повышение резистентности телят опытной группы. Масса телят опытной группы достоверно увеличивалась с 7-х суток исследования до $20 \%$ относительно контрольной группы.

Ключевые слова: Резистентность, продуктивность, сохранность, пробиотик, биовестин.

Профилактика различных заболеваний телят в постколостральный периоды имеет свои особенности. В это время у животных стабилизируется фагоцитарная активность лейкоцитов, появляются гуморальные факторы защиты организма, в хозяйствах проводится перегруппировка молодняка, изменяется режим его кормления. В результате отмечается снижение общей резистентности организма телят, приводящее к развитию у них различных заболеваний, в том числе, бактериальной и вирусной этиологии [3].
\end{abstract}


Традиционные схемы лечения больных животных с использованием антибактериальных, сульфаниламидных, нитрофурановых и других синтетических препаратов не всегда приводит к положительному результату. Их применение оказывает отрицательное воздействие на иммунный статус молодняка, что затягивает процесс окончательного выздоровления. В этой связи проблема поиска новых экологически безопасных препаратов для профилактики различных болезней молодняка и повышения его иммунного статуса - одна из актуальных задач на сегодняшний день.

С накоплением данных о физиологическом состоянии животных и, прежде всего, состояния резистентности, включая гематологический и биохимический статус, представляется возможность более объективно оценивать их адаптационные способности, разрабатывать рациональные способы направленной иммунокоррекции [4].

Целью наших исследований являлось изучение морфологического состава крови телят при применении биовестина.

\section{Материалы и методы исследования}

Исследования проведены на базе учебного хозяйства «Кузовлево» Томского района, Томской области, где содержится более 100 голов чернопестрого скота. Для исследования морфологического состава крови телят, в условиях применения биовестина, были сформированы 2 группы животных, 3 -7 дней жизни в условиях индивидуального и группового содержания. Телята в каждую группу отобраны по принципу пар аналогов, с учетом возраста, пола, массы, физиологического состояния.

Животные находиться в одинаковых условиях кормления и содержания.

Телятам опытной группы (10 голов), отобранных по принципу аналогов: черно-пестрая порода, телочки и бычки 45-50 кг, с 3 дня жизни, дополнительно выпаивался Биовестин по следующей схеме: 0.2 мл/кг, перед основным кормлением, в течение 21 дня. 
Биовестин разработан ЗАО «Био-Веста» г. Новосибирск, представляет собой эмульсию однородной консистенции, цветом от кремового до светлокоричневого. Эмульсия содержит щтамм живых бифидобактерий Bifidobacterium adolescentis MC-42 в количестве не менее $1 * 107$ клеток в 1 см3, в качестве вспомогательного вещества - обезжиренное молоко.

Вторая группа телят (10 голов) служила контролем и препарата не получала.

У телят из каждой группы на 1-, 7-, 15-, 20- сутки, и по достижению месячного возраста, каждые 30 дней изучался морфологический состав периферической крови.

Полученные результаты статистически обрабатывались с использованием t-критерия Стьюдента в программе Excel.

\section{Результаты и их обсуждение}

Морфологические показатели крови позволяют использовать их для оценки состояния обменных процессов в организме животных. Наиболее важным морфологическим показателем крови является содержание эритроцитов. Основная функция эритроцитов - транспорт кислорода от легких к тканям и углекислого газа от тканей к легким. Эритроциты переносят также адсорбированные на их поверхности питательные и биологически активные вещества, участвуют в регуляции кислотно-щелочного равновесия и водносолевого обмена в организме. Они принимают участие в нормализации состояния иммунной системы, а также в регуляции свертывания крови .

Сложный механизм окислительно-восстановительных процессов в организме телят находится в прямой связи с эритропоэзом. Анализ полученных данных свидетельствует о том, что содержание эритроцитов у телят опытной группы на 7-е, 100-е, 120-е сутки исследования было выше относительно контроля, соответственно динамика содержания гемоглобина повторяла динамику эритроцитов (табл. 1). 
Морфологический состав крови телят при применении биовестина

\begin{tabular}{|c|c|c|c|c|c|c|c|c|}
\hline \multirow{2}{*}{ Группа } & \multicolumn{8}{|c|}{ Содержание эритрочитов $\times 10^{12} / L$} \\
\hline & $\begin{array}{c}\text { 3-е } \\
\text { сутки }\end{array}$ & $\begin{array}{c}\text { 7-е } \\
\text { сутки }\end{array}$ & $\begin{array}{l}\text { 15-е } \\
\text { сутки }\end{array}$ & $\begin{array}{c}\text { 20-е } \\
\text { сутки }\end{array}$ & $\begin{array}{l}\text { 40-е } \\
\text { сутки }\end{array}$ & $\begin{array}{l}\text { 70-е } \\
\text { сутки }\end{array}$ & $\begin{array}{l}\text { 100-е } \\
\text { сутки }\end{array}$ & 120-е сутки \\
\hline $\begin{array}{c}\text { Контрольна } \\
\text { я }\end{array}$ & $\begin{array}{c}6,68 \pm 0,6 \\
8\end{array}$ & $\begin{array}{c}6,79 \pm 0,6 \\
7\end{array}$ & $\begin{array}{c}6,92 \pm 0,6 \\
9\end{array}$ & $\begin{array}{c}7,40 \pm 0,6 \\
7\end{array}$ & $\begin{array}{c}8,06 \pm 0,6 \\
6\end{array}$ & $\begin{array}{c}5,22 \pm 0,3 \\
9\end{array}$ & $\begin{array}{c}6.85 \pm 0.4 \\
2\end{array}$ & $6,73 \pm 0,49$ \\
\hline Опытная & $\begin{array}{c}7,69 \pm 0,2 \\
5\end{array}$ & $\begin{array}{c}7,43 \pm 0,7 \\
0\end{array}$ & $\begin{array}{c}7,85 \pm 0,7 \\
7\end{array}$ & $\begin{array}{c}7,21 \pm 0,8 \\
7\end{array}$ & $\begin{array}{c}8,84 \pm 0,7 \\
7\end{array}$ & $\begin{array}{c}4,51 \pm 0,5 \\
3\end{array}$ & $\begin{array}{c}7.65 \pm 0,2 \\
5^{*}\end{array}$ & $7,95 \pm 0,47^{*}$ \\
\hline
\end{tabular}

\begin{tabular}{|c|c|c|c|c|c|c|c|c|}
\hline \multirow{2}{*}{ Группа } & \multicolumn{8}{|c|}{ Содержсание гемоглобина, $g / L$} \\
\hline & 3-е сутки & 7-е сутки & $\begin{array}{c}\text { 15-е } \\
\text { сутки }\end{array}$ & $\begin{array}{l}\text { 20-е } \\
\text { сутки }\end{array}$ & $\begin{array}{l}\text { 40-е } \\
\text { сутки }\end{array}$ & $\begin{array}{c}\text { 70-е } \\
\text { сутки }\end{array}$ & $\begin{array}{l}100-\mathrm{e} \\
\text { сутки }\end{array}$ & $\begin{array}{l}120-\mathrm{e} \\
\text { сутки }\end{array}$ \\
\hline $\begin{array}{c}\text { Контрольн } \\
\text { ая }\end{array}$ & $85,8 \pm 0,50$ & $86,3 \pm 0,38$ & $85,8 \pm 0,89$ & $80,6 \pm 0,85$ & $\begin{array}{c}94,6 \pm 0,6 \\
9\end{array}$ & $99,4 \pm 0,81$ & $96,6 \pm 0,43$ & $98,3 \pm 0,19$ \\
\hline Опытная & $94,5 \pm 0,17$ & $\begin{array}{c}91,5 \pm 0,79 \\
*\end{array}$ & $\begin{array}{c}90,4 \pm 0,81 \\
*\end{array}$ & $81,4 \pm 0,99$ & $\begin{array}{c}86,4 \pm 0,4 \\
1\end{array}$ & $\begin{array}{c}103,2 \pm 0,23 \\
*\end{array}$ & $\begin{array}{c}105,2 \pm 0,42 \\
*\end{array}$ & $\begin{array}{c}104,8 \pm 0,39 \\
*\end{array}$ \\
\hline
\end{tabular}

Примечание: * - достоверные различия относительно контрольной группы, $\mathrm{P}<0,05$

Лейкоцитарная система организма чутко реагирует на любые изменения, происходящие в организме под воздействием внешних факторов. Эти реакции связаны с перестройкой работы органов гемопоэза. В результате может осуществляться усиленная выработка как всех, так и отдельных групп лейкоцитов или перераспределение их содержания в крови животного [1].

Таблииа 2

Лейкограмма телят при применении биовестина

\begin{tabular}{|c|c|c|c|c|c|c|c|c|}
\hline \multirow{2}{*}{ Группа } & \multicolumn{8}{|c|}{ лимфоччиты × $10^{9} / \mathrm{L}$} \\
\hline & 3-е сутки & 7-е сутки & 15-е сутки & 20-е сутки & 40-е сутки & $\begin{array}{c}\text { 70-е } \\
\text { сутки }\end{array}$ & $\begin{array}{l}100-е \\
\text { сутки }\end{array}$ & 120-е сутки \\
\hline
\end{tabular}




\begin{tabular}{|c|c|c|c|c|c|c|c|c|}
\hline \multirow{2}{*}{ Контрольная } & $\begin{array}{c}60,37 \pm 0,8 \\
3\end{array}$ & $\begin{array}{c}66,83 \pm 0,3 \\
6\end{array}$ & $16,37 \pm 0,51$ & $11,71 \pm 1,32$ & $17,39 \pm 0,45$ & $4,45 \pm 0,10$ & $4,84 \pm 0,48$ & $5,14 \pm 0,51$ \\
\hline Опытная & 2 & $7 *$ & $*$ & $*$ & & & & \\
\hline
\end{tabular}

\begin{tabular}{|c|c|c|c|c|c|c|c|c|}
\hline \multirow[b]{2}{*}{ Группа } & \multicolumn{8}{|c|}{ Гранулоциты × $10^{9} / \mathrm{L}$} \\
\hline & 3-е сутки & 7-е сутки & $\begin{array}{c}\text { 15-е } \\
\text { сутки }\end{array}$ & 20-е сутки & 40-е сутки & 70-е сутки & $\begin{array}{l}\text { 100-е } \\
\text { сутки }\end{array}$ & $\begin{array}{l}\text { 120-е } \\
\text { сутки }\end{array}$ \\
\hline $\begin{array}{c}\text { Контроль } \\
\text { ная }\end{array}$ & $16,71 \pm 1,08$ & $14,67 \pm 1,29$ & $\begin{array}{c}18,66 \pm \\
0,45\end{array}$ & $28,86 \pm 0,16$ & $24,32 \pm 0,14$ & $11,77 \pm 0,36$ & $\begin{array}{c}11,67 \pm 1,2 \\
5\end{array}$ & $13,63 \pm 1,32$ \\
\hline Опытная & $16,09 \pm 0,14$ & $15,42 \pm 1,58$ & $\begin{array}{c}20,51 \pm 0,6 \\
8\end{array}$ & $20,24 \pm 0,6^{*}$ & $26,21 \pm 0,25$ & $21,45 \pm 0,96 *$ & $\begin{array}{c}24,21 \pm 0,2 \\
5\end{array}$ & $23,11 \pm 0,45$ \\
\hline
\end{tabular}

\begin{tabular}{|c|c|c|c|c|c|c|c|c|}
\hline \multirow{2}{*}{ Группа } & \multicolumn{8}{|c|}{$\begin{array}{l}\text { Mid\# (содержание смеси моноцитов, эозинофилов, базофилов и незрелых клеток) } \\
\qquad \times 10^{9} / L\end{array}$} \\
\hline & 3-е сутки & 7-е сутки & 15-е сутки & 20-е сутки & 40-е сутки & 70-е сутки & $\begin{array}{l}\text { 100-е } \\
\text { сутки }\end{array}$ & 120-е сутки \\
\hline $\begin{array}{c}\text { Контрольн } \\
\text { ая }\end{array}$ & $2,51 \pm 0,28$ & $2,62 \pm 0,43$ & $3,29 \pm 0,20$ & $2,18 \pm 0,23$ & $3,54 \pm 0,05$ & $2,16 \pm 0,11$ & $2,22 \pm 0,25$ & $2,51 \pm 0,13$ \\
\hline Опытная & $2,79 \pm 0,96$ & $6,57 \pm 1,11$ & $4,97 \pm 0,69$ & $3,98 \pm 0,45$ & $3,62 \pm 0,37$ & $4,12 \pm 0,31^{*}$ & $4,95 \pm 0,34$ & $4,89 \pm 0,39 *$ \\
\hline
\end{tabular}

Примечание: * - достоверные различия относительно контрольной группы, $\mathrm{P}<0,05$

Как отмечают авторы, кровь телят сразу после рождения имеет нейтрофильный профиль, эозинофилы в это время встречаются крайне редко, к месячному возрасту в лейкограмме превалируют лимфоциты [2]. Полученные нами данные (таблица 2) имеют такую же тенденцию, но в лейкограмме телят опытной группы количество лимфоцитов выше относительно контроля к 15 суткам на 36,5\% $(\mathrm{P}<0,05)$, на 20 сутки - 12,2\%, на 40 сутки - 13,2\%.

Шумский В. А. [5] утверждает что пробиотики стимулируют органы иммуногенеза организма животных. Это происходит главным образом за счёт гиперплазии лимфоидной ткани, с увеличением клеток Т- и В-лимфоцитов, а также плазматических клеток и макрофагов. 
Динамика количества моноцитов соответствует динамике лимфоцитов.

Моноциты являются специфическими клетками крови и носят защитную функцию, именно они первыми отвечают агрессией на внедрение в живой организм инородных тел. В данном случае это могут быть отмершие клетки патогенных и условно-патогенных микроорганизмов:

Увеличение числа лимфоцитов и моноцитов способствует повышению реакций специфического иммунитета и может свидетельствовать о повышении клеточных факторов иммунитета.

Таким образом, при применении биовестина у телят повышается неспецифическая резистентность организма, животные менее подвержены диспепсическим расстройствам. Увеличивается поедаемость корма, и улучшается продуктивность животных, что выражается в увеличении среднесуточных приростов живой массы. 


\section{Литература:}

1. Ионов П. С. и др., Диагностическая и терапевтическая техника в ветеринарии// Москва Изд-во Колос, 1979 -223 с.

2. Пахмутов В. М. Сведения о незаразных болезнях сельскохозяйственных животных в субъектах Российской Федерации в 2005 г. /В. М. Пахмутов, И. И. Балковой, Ю. В. Бабенко, В. С. Довбыш, Л. М. Сивакова//Ветеринарный консультант.-2006.-№6.-С.4-7.

3. Субботин В. В., Ивкин И. С., Самохин В.Т. и др. Научно обоснованная система получения здорового молодняка и профилактика желудочнокишечных болезней новорожденных телят// Рекомендации. - М., 2002;

4. Томашевская Е. П., Эффективность и перспективы применения пробиотиков // Достижения науки и техники АПК. - 2006. -№4. - С. 24;

5. Шумский В. А. Влияние пробиотиков в комплексе с адсорбентом на физиологический статус телят, их рост и развитие.// ВАК 03.00.13 Физиология. // Белгород 2005. - с. 45; 